\title{
Prevalence of Intestinal Parasitic Infestations in and Around Ambajogai, Maharashtra
}

\author{
Sourabh Chakraborty ${ }^{1}$ and S.L. Nilekar ${ }^{2}$ \\ Department of Microbiology, SRTR GMC, Ambajogai, Beed, Maharashtra, 431517, India \\ *Corresponding author
}

\section{Keywords}

Intestinal parasites, Infestations,

Prevalence, Stool

Article Info

Accepted:

07 February 2019

Available Online:

10 March 2019

\section{A B S T R A C T}

Intestinal parasitic infestations are among the ten most common infestations of the world. Intestinal parasitic infestations are distributed throughout the world, with high prevalence in poor and socio-economically deprived communities in the tropics and subtropics. The overall prevalence of intestinal parasites has been reported in the range of $11.3 \%$ - $90 \%$ by several authors in India. In India, Chandigarh, Tamil Nadu and Maharashtra prevalence is $>30 \%$. Worm's infestation is one of the major causes of childhood malnutrition, anemia, stunted physical and mental growth and psycho social problems. The present study was carried out to know the prevalence of intestinal parasitic infestations so that early diagnosis and institution of appropriate therapy is possible so as to control parasitic infestations promptly. The study was carried out in the Department of Microbiology at our hospital from January 2017 to June 2018. A total of 880 patients were investigated for parasites from their stool samples. Specimens were collected in a suitable, clean, wide mouthed container and were examined using macroscopic and microscopic technique (saline and iodine mount). Males (<10 years age group) were more commonly affected. Most common presenting symptoms were Diarrhoea/loose motion $(47.95 \%)$ followed by abdominal discomfort/pain in abdomen (22.61\%). Ascaris lumbricoides $(3.40 \%)$, Taenia spp (2.39\%), Hookworm (2.05\%), Entamoeba histolytica (2.61\%), Cryptosporidium parvum (1.82\%) were the common isolates. Discussion: $16.93 \%$ samples were positive for parasites (by saline and iodine wet mount) which can lead to several health issues. So the intestinal parasitic infestations should not be ignored.

\section{Introduction}

The discovery of human parasites goes way back to Antony van Leeuwenhoek, a Dutch draper of Holland, who used single lens microscopes to observe microscopic organisms in feces of man and animals and named them as animalcules. Parasites have been the bane of mankind for centuries and continue to cause high morbidity and sufferings in world - especially in the developing countries like India ${ }^{1}$.

Intestinal parasitic infestations are among the ten most common infestations of the world. Intestinal parasitic infestations are distributed 
throughout the world ${ }^{2}$, with high prevalence in poor and socio-economically deprived communities in the tropics and subtropics ${ }^{3}$. These infestations continue to be a global health problem, particularly among children in poor communities in developing countries ${ }^{4}$.

The World Health Organization (WHO) estimates that approximately 50 million people worldwide endure insidious amoebic infestation each year, resulting in 40-100 thousand deaths yearly ${ }^{5}$. It is estimated that number of people affected with hookworm, roundworm, and whipworm in the world is estimated to be 900 million, 1 billion, 800 million respectively ${ }^{6}$. The overall prevalence of intestinal parasites have been reported in the range of $11.3 \%-90 \%$ by several authors in India ${ }^{7,8}$. In India, Chandigarh, Tamil Nadu and Maharashtra prevalence is $>30 \%{ }^{9}$.

The impure drinking water, low socioeconomic state, poor sanitation coupled with low literacy rates of parents particularly the mothers are the main causes. Worm's infestation is one of the major causes of childhood malnutrition, anemia, stunted physical and mental growth and psycho social problems. The reason for being a global public health problem is that helminthic infestation have largely been over looked by clinician, because although worms can cause severe clinical problems, patients rarely report at health centre due to its slow progress of the signs and symptoms ${ }^{10,11}$.

Most of the parasitic diseases cannot be conclusively diagnosed only on the basis of clinical features and physical examination. These require the support of the laboratory to firmly establish the diagnosis. Various methods are now available in the laboratory to diagnose parasitic diseases such as: direct demonstration of adult parasites/ segments, Microscopic examination of body fluids and tissues, cultural methods, Xenodiagnosis, animal inoculation, histopathology and immunodiagnosis ${ }^{12}$.

There is paucity of information about proportion of different parasitic infestations. The present study was carried out to know the prevalence of intestinal parasitic infestations so that early diagnosis and institution of appropriate therapy is possible so as to control parasitic infestations promptly.

\section{Materials and Methods}

The study was carried out in the Department of Microbiology at our hospital from January 2017 to June 2018. A total of 880 patients with persistent diarrhea, weight loss, intestinal malabsorption and various types of anaemia, attending outpatient/ inpatient department of Medicine, Paediatrics, Obstetrics and Gynaecology were investigated for parasites from their stool samples.

Detailed clinical history was noted. Past history of diarrhoea, drug treatment, radiological procedures (Barium studies) or any major illness were noted.

\section{Collection of specimen}

All stool specimens were collected in a suitable, clean, wide mouthed container like a plastic container with a light fitting lid, waxed cardboard box, or match box and handled carefully because each specimen represents a potential source of infectious material. Care was taken to avoid contamination with water, urine, or disinfectants.

Liquid stools, soft stools, hard stools were examined or preserved within 30 minutes, 1 hours, 24 hours of passage respectively. Normally passed stools were preferred, although samples obtained after purgative (sodium sulphate) or high saline enema was also used. 
Examination of fresh specimens was necessary for observing motility of protozoan parasites $^{13}$.

\section{Processing of specimen}

\section{Macroscopic examination}

Stool was examined for its consistency, color, odor, and presence of blood or mucus. In some instances, parasites may be seen on gross inspection, as in the case of roundworm, pinworm, or tapeworm proglottids.

\section{Microscopic examination}

A drop of saline was placed (if amoebic dysentery is suspected warm saline $37^{\circ} \mathrm{C}$ was used) on the left side of the slide and a drop of Lugol's iodine on the right. Using a wire loop or a piece of stick, mix a small amount of feces (2 $\mathrm{mg}$ of feces, approximately matchstick- head size amount) and make a smooth suspension. A coverslip was placed on each of these suspensions ${ }^{13}$.

The preparations were examined systematically with low power objective; if suspicious objects were noticed switch to high power objective to observe details ${ }^{14}$. The presence of Charcot- Leyden crystals and cellular exudates such as pus cells, RBCs and macrophages were looked for ${ }^{13}$.

Trophozoites of Entamoeba histolytica are large, actively motile (freshly passed stool), irregular, with granular endoplasm and clear ectoplasm. They were observed for amoeboid motility, crawling or gliding movement. Pseudopodia formation and motility are inhibited at low temperature ${ }^{15}$. Warmth was provided by keeping the wet mounts near lighted electric bulb for amoebic movement. Trophozoites were differentiated from pus cells by their size, ratio of nuclear material to cytoplasm, nuclear and cytoplasmic characteristics $^{16}$.
The trophozoite of Giardia lamblia is in the shape of a tennis racket (heart shaped or pyriform shaped). The trophozoites are motile, resembling falling leaf. It is bilaterally symmetrical and possesses: 1 pair of nuclei, 4 pairs of flagella, 1 pair of axosystoles ${ }^{17}$.

Various helminthes have distinct morphology of eggs, which was used to differentiate the helminthes ${ }^{18}$.

\section{Saline wet mount}

Saline preparation was employed to demonstrate worm eggs, larvae, protozoal trophozoites as well as RBCs and $\mathrm{WBCs}^{19}$.

\section{Iodine mount}

Iodine mount was employed to demonstrate the cysts under high power objective. The stained cysts were examined for nuclei, glycogen mass, chromatid bodies ${ }^{19}$. Protozoan cyst stained with iodine show yellow- gold cytoplasm, brown glycogen material, and pale refractile nuclei ${ }^{13}$.

The specimen showing oocysts resembling oocysts of cryptosporidium parvum, Isospora belli and cyclospora were further confirmed by modified zeihl neelsen staining ${ }^{19}$.

\section{Preservation of sample}

After the complete processing of stool specimen was over 3 parts of $10 \%$ formalin were added to one part of feces for preservation. After treatment with $10 \%$ formol saline, screw capped tops were fitted tightly and the containers were stored at room temperature $^{19}$.

\section{Results and Discussion}

In the present study, during the one and half year study period from January 2017 to June 
2018, 880 symptomatic patients with diarrhea, vomiting, abdominal pain and weight loss were studied.

Out of the 880 patients, $509(57.85 \%)$ were male patients and 371 (42.15\%) were female patients. Most common age group affected was < 10 years. 256 (29.09\%) patients belonged to the age group of $<10$ years, followed by $150(17.05 \%)$ patients in 11- 20 years of age group and 146 (16.59\%) patients belonged to the age group of $21-30$ years. The lowest affected (4.20\%) age group was 61 years and above age group (Table 1 and Fig. 1).

Out of the 880 patients, 422 (47.95\%) patients presented with Diarrhoea/loose motion followed by 199 (22.61\%) patients presented with abdominal discomfort/pain in abdomen. $70(7.95 \%)$ patients presented with Weight loss and $67(7.61 \%)$ patients presented with anemia. A total of 58 (6.59\%) patients presented with miscellaneous symptoms. There were 24 (2.73\%) patients who came for routine investigations and had no specific symptoms. The other symptoms were loss of appetite and chronic pain abdomen in $20(2.27 \%)$ patients each (Table 2 and Fig. 2).

Table 3 shows different intestinal parasites detected by saline and iodine mount. The most common isolate was Ascaris lumbricoides in 30(3.40\%) samples, followed by Taenia spp. in 21(2.39\%) samples and Hookworm in 18 (2.05\%) samples. Trichuris trichura was isolated from $15(1.70 \%)$ samples and Hymenolepis nana from 12 (1.36\%) samples.

Entamoeba histolytica was the most commonly isolated extracellular protozoan in 23(2.61\%) samples while7 $(0.80 \%)$ stool sample was positive for Giardia lamblia. Cryptosporidium parvum was observed in 16 (1.82\%) samples, was the most commonly isolated intracellular protozoan, and followed by Isospora belli was isolated in $01(0.11 \%)$ sample (Fig. 3).

The present study was conducted on 880 patients attending the OPD and/ or admitted in the hospital due to persistent diarrhea, weight loss, intestinal mal absorption and whose stool sample was received in the Department of Microbiology.

Table.1 Age and sex distribution of the patients

\begin{tabular}{|l|l|l|l|l|l|l|}
\hline Age in years & Males & $\%$ & Females & $\%$ & Total & \%o of patients (n): 880 \\
\hline$<\mathbf{1 0}$ & 136 & $15.45 \%$ & 120 & $13.63 \%$ & 256 & $29.09 \%$ \\
\hline $\mathbf{1 1 - 2 0}$ & 89 & $10.11 \%$ & 61 & $6.93 \%$ & 150 & $17.05 \%$ \\
\hline $\mathbf{2 1 - 3 0}$ & 81 & $9.20 \%$ & 65 & $7.39 \%$ & 146 & $16.59 \%$ \\
\hline $\mathbf{3 1 - 4 0}$ & 75 & $8.52 \%$ & 46 & $5.22 \%$ & 121 & $13.75 \%$ \\
\hline $\mathbf{4 1 - 5 0}$ & 57 & $6.47 \%$ & 45 & $5.11 \%$ & 102 & $11.59 \%$ \\
\hline $\mathbf{5 1 - 6 0}$ & 45 & $5.11 \%$ & 23 & $2.61 \%$ & 68 & $7.72 \%$ \\
\hline $\mathbf{6 1}$ and above & 26 & $2.95 \%$ & 11 & $1.25 \%$ & 37 & $4.20 \%$ \\
\hline Total & 509 & $57.85 \%$ & 371 & $42.15 \%$ & 880 & $100 \%$ \\
\hline
\end{tabular}


Table. 2 Various clinical presentations of patients

\begin{tabular}{|l|l|l|l|}
\hline Sr. No & Signs and symptoms & No of cases & $\begin{array}{l}\text { \% (Total } \\
\text { subjects) }\end{array}$ \\
\hline $\mathbf{1}$ & Diarrhoea/ Loose motion & 422 & 47.95 \\
\hline $\mathbf{2}$ & Abdominal discomfort/ Pain in abdomen & 199 & 22.61 \\
\hline $\mathbf{3}$ & Weight loss & 70 & 7.95 \\
\hline $\mathbf{4}$ & Anaemia & 67 & 7.61 \\
\hline $\mathbf{5}$ & Miscellaneous & 58 & 6.59 \\
\hline $\mathbf{6}$ & Routine/ No specific symptoms & 24 & 2.73 \\
\hline $\mathbf{7}$ & Chronic pain abdomen & 20 & 2.27 \\
\hline $\mathbf{8}$ & Loss of appetite & 20 & 2.27 \\
\hline & Total & 880 & 100 \\
\hline
\end{tabular}

Table.3 Different intestinal parasites detected by saline and iodine wet mount

\begin{tabular}{|l|c|c|c|}
\hline Sr.No & Helminths & No of Isolates & Percentage of isolates \\
\hline $\mathbf{1}$ & Ascaris lumbricoides & 30 & $3.40 \%$ \\
\hline $\mathbf{2}$ & Taenia spp. & 21 & $2.39 \%$ \\
\hline $\mathbf{3}$ & Hookworm & 18 & $2.05 \%$ \\
\hline $\mathbf{4}$ & Trichuris trichiura & 15 & $1.70 \%$ \\
\hline $\mathbf{5}$ & Hymenolepsis nana & 12 & $1.36 \%$ \\
\hline $\mathbf{6}$ & Strongyloides stercoralis & 04 & $0.45 \%$ \\
\hline $\mathbf{7}$ & Enterobius vermicularis & 01 & $0.11 \%$ \\
\hline & Extracellular protozoans & & $2.61 \%$ \\
\hline $\mathbf{8}$ & Entamoeba histolytica & 23 & $0.80 \%$ \\
\hline $\mathbf{9}$ & Giardia lamblia & 07 & $0.11 \%$ \\
\hline & Entamoeba coli & 01 & $1.82 \%$ \\
\hline & Intracellular protozoan & & $0.11 \%$ \\
\hline $\mathbf{1 0}$ & Cryptosporidium parvum & 16 & $16.93 \%$ \\
\hline $\mathbf{1 1}$ & Isospora belli & 01 & 149 \\
\hline & Total & & \\
\hline
\end{tabular}

Fig.1 Age and sex distribution of the patients

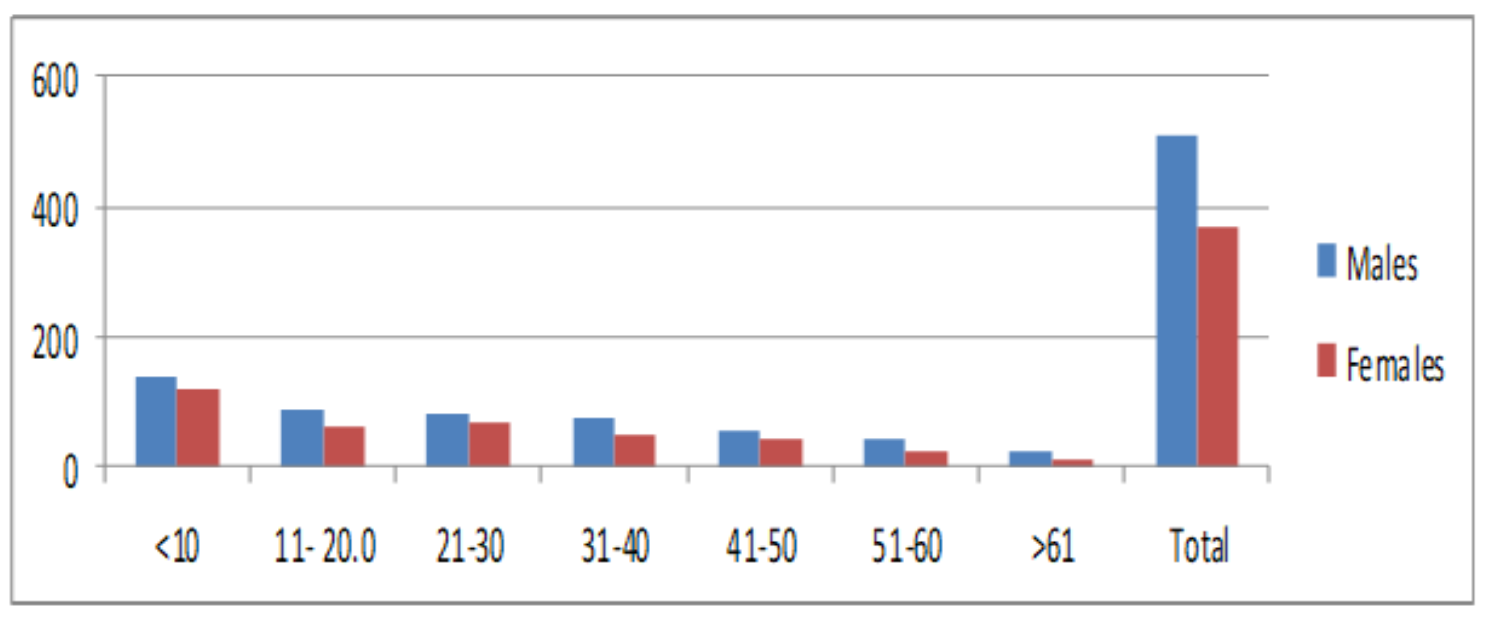


Fig.2 Various clinical presentations of patients

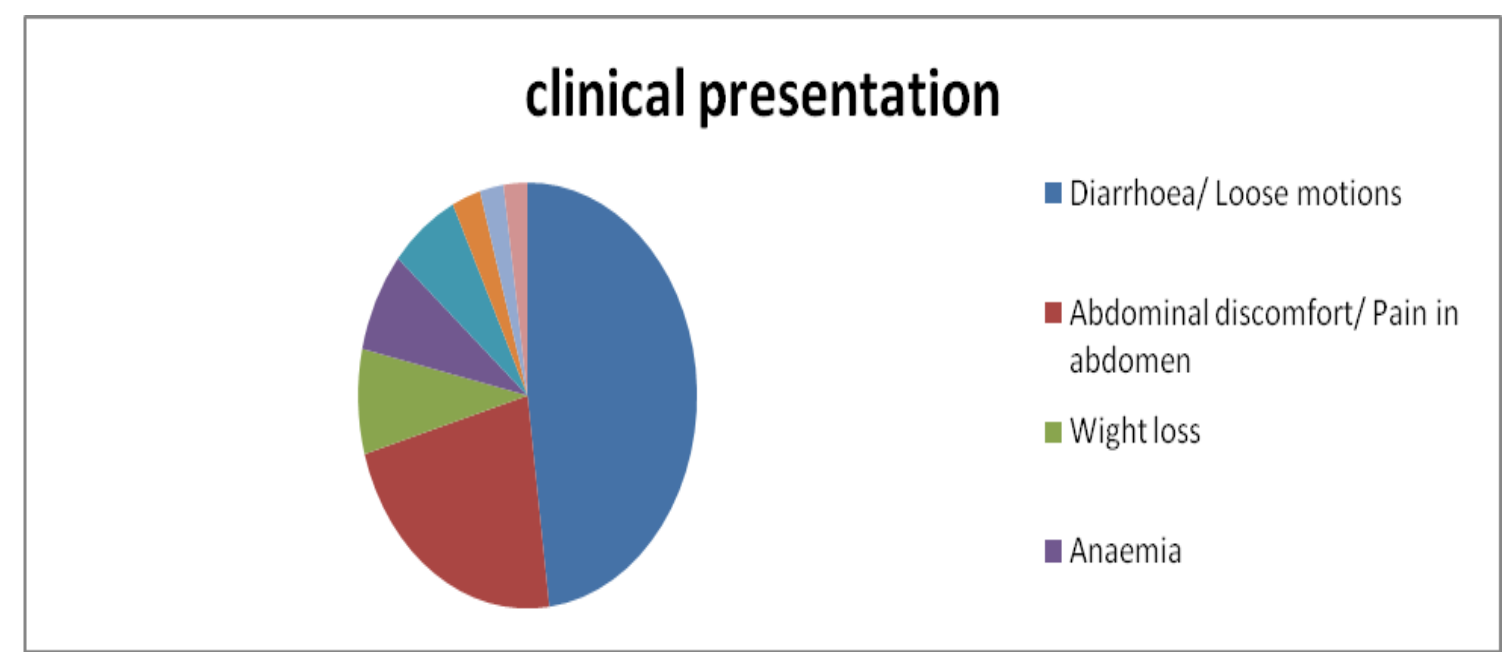

Fig.3 Different intestinal parasites detected on saline and iodine wet mount

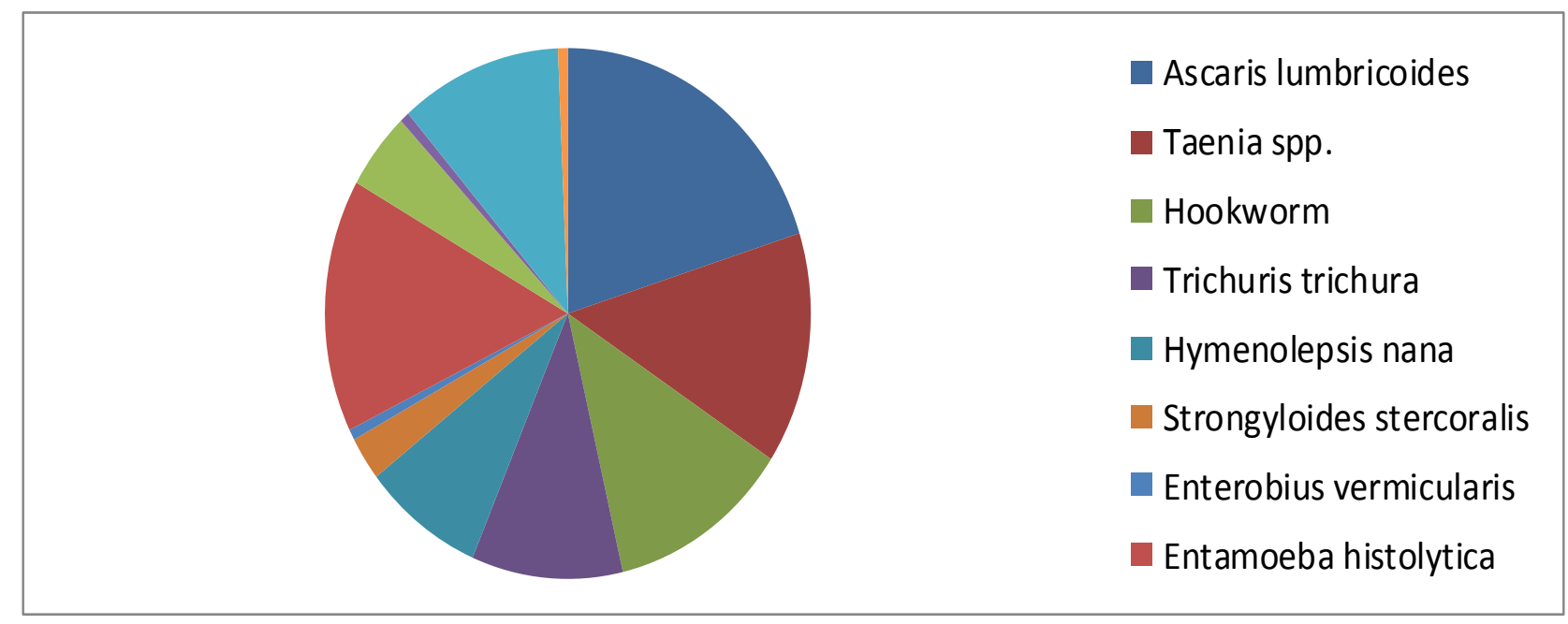

Maximum number of the samples was from < 10 years age group (29.09\%) followed by $17.05 \%$ samples were from 11- 20 years of age group. Almost half of the samples $(46.14 \%)$ were obtained from among those within 20 years of age. Prevalence of gastrointestinal disorders has been reported to be higher in age group <20 years from Indian subcontinent. Khan et al., and Beenajad et al., (2015) also observed that around $44 \%$ and $49.80 \%$ of their study population with gastrointestinal disorders was within 20 years of $\operatorname{age}^{20,21}$. The tendency to consume unhygienic and street food, experimentation with different food stuffs and general lower immunity in young population could be the reason for this ${ }^{20}$.

Among specimen obtained, majority were from males 509 (57.85\%). Only 371 (42.15\%) samples comprised of females. Such findings have also been observed in other geographical areas (Agi, 1995; Koroosh, 1997; Sethi et al., 2000; Rao et al., 2003; Choubasia et al., 2012).

This is in contrast with the observations made by Chang et al., who observed that 
gastrointestinal disorders were more common in females as compared to males ${ }^{23}$. Halder et $a l$. , too in their longitudinal study evaluated that gastrointestinal disorders were more in females $(52 \%)$ than males $(48 \%)^{24}$. The others reported similar rate in both sexes (Patel et al., 1986; Hedge and Patel et al., 1986) ${ }^{25,26}$. This may be related to the daily activity of the subjects rather than $\operatorname{sex}^{22}$. The result in our study could be because of the difference in hospital healthcare seeking behavior of Indian population mostly in rural area wherein females are generally tended to seek hospital healthcare only for life-threatening problems and for minor ailments they generally seek home remedies ${ }^{27,28}$.

Diarrhoea/loose motions, abdominal discomfort/pain in abdomen and anemia were some of the most common clinical symptoms of subjects enrolled in the study. These are some of the commonly associated symptoms with infectious intestinal diseases. Diarrhoea/loose motions are most common among the younger age groups and considering the fact that almost half the cases in the present study were below 20 years of age this finding can be explained easily. In our study $422(47.95 \%)$ patients presented with diarrhoeal symptoms, 199 (22.61\%) patients presented with complaints of abdominal discomfort. $70(7.95 \%)$ patients complained of weight loss and 67 (7.61\%) patients presented with signs of anaemia. In a study by Borooah et al., (2004) the prevalence of diarrhoea among children has been reported to be as high as $61.7 \%^{29}$. Beena Jad et al., (2015) also observed Diarrhoea as the most common presenting symptom in $45.8 \%$ cases $^{30}$.

In the present study, the prevalence of intestinal parasitic infestation by saline and iodine wet mount technique was $16.93 \%$ (149 samples were positive in saline and iodine mount). Shanker Venkatesh et al., (2016) reported a prevalence of $12.20 \%$ by saline and iodine mount ${ }^{31}$. The prevalence of the intestinal parasitosis reported by Hersh Ahmad Amin et al., (2015) was $22.6 \%$ using saline and iodine mount technique ${ }^{32}$. Ritu Garg et al., (2017) and MagdiBayoumi et al., (2016) reported prevalence of intestinal parasitic infestation was $36 \%$ and $16.22 \%$ respectively using saline and iodine mount technique ${ }^{33,34}$, whereas BeenaJad et al., reported prevalence of $7.8 \%$ by saline and iodine wet mount ${ }^{30}$.

Among helminths Ascaris lumbricoides was the most common parasite isolated in our study, showed positivity of $3.40 \% \quad$ (30 samples), followed by Taenia spp (2.39\%, 21 samples). According to Singh Randhir et al., (2017) Ascaris lumbricoides has been reported in $19.14 \%$ and Taenia spp in $00.25 \%$ of patients ${ }^{35}$. According to Shakya et al., (2009) prevalence of Ascaris lumbricoides was $6.70 \%$ and for Taenia spp it was $0.54 \%^{36}$, which was much lower. Choubisa et al., reported in 2012, prevalence of Ascaris lumbricoides was $4.46 \%$ and for Taenia spp it was $5.35 \%^{22}$.

Entamoeba histolytica was the most commonly isolated extracellular protozoan. Entamoeba histolytica was observed in 23 $(2.61 \%)$ samples, followed by Giardia lamblia were isolated from 7 (0.80\%) samples in our study.

In 2009 Shakya et al., reported prevalence of Entamoeba histolytica was $8.01 \%$ and that of Giardia lamblia was $1.17 \%{ }^{36}$. According to Choubisa et al., (2012), Entamoeba histolytica was present in $8.92 \%$ of the samples $^{22}$.

In conclusion, $16.93 \%$ samples were positive for parasites by saline and iodine wet mount. Proportionately helminthic infestation is more compared to protozoal infestations. Our study 
concludes that there is need of implementation of few practices like, consumption of properly cooked food, environmental hygiene, provision for clean water, deworming campaigns, not walking bare foot especially in rural area and most important is health education.

\section{References}

1. Dr. Sucheta J. Lakhani MRR-, Khara, Dr. Sunanda Joshi DSV. Intestinal Parasitic Infestations Among School Children in Piparia Village, Vadodara District. IJSR Int J Sci Res. 2013; 2(12): 434-6.

2. Khurana S, Aggarwl A MN. Comparative analysis of intestinal parasitic infections in slum, rural and urban populations in and around union territory, Chandigarh. J Commun Dis. 2005; 37(3): 239.

3. World Health Organization. Major parasitic infections: A global view. World Health Stat Q 39. In: Parasitic Diseases Programme. 1986. p. 145-60.

4. Brooker S, Clements ACA, Bundy DAP. Global Epidemiology, Ecology and Control of Soil-Transmitted Helminth Infections. Adv Parasitol. 2006; 62(5): 221-61.

5. Jayaram Paniker, CK. Paniker's Textbook of Medical Parrasitology. 7th edn. Ghosh S, editor. JAYPEE; 2013. 173-175 p.

6. Jayaram Paniker, CK. Paniker's Textbook of medical parrasitology. 7th edn. Sougata Ghosh, editor. JAYPEE; 2013. 182,195,172.

7. Kang G, Mathew MS, Rajan DP, Daniel JD, Mathan MM, Mathan VI, et al., Prevalence of intestinal parasites in rural Southern Indians. Trop Med Int Heal [Internet]. 1998;3(1):70-5. Available from: http://www.ncbi.nlm.nih.gov/pubmed/9484 973

8. Marothi Y, Singh B. Prevalence of intestinal parasites at Ujjain, Madhya Pradesh, India: Five-year study. African J Microbiol Res. 2011;5(18):2711-4.

9. Jayaram Paniker, CK. Paniker's Textbook of medical parrasitology. 7th edn. Sougata Ghosh, editor. JAYPEE; 2013. 14-17 p.

10. Kappus KD, Lundgren RG, Juranek DD, Roberts JM, Spencer HC. Intestinal parasitism in the United States: Update on a continuing problem. Am J Trop Med Hyg. 1994; 50(6): 705-13.

11. Okyay P, Ertug S, Gultekin B, Onen O BE. Intestinal parasites prevalence and related factors in school children, a western city sample- Turkey. BMC Public Health. 2004; 22(4): 64.

12. Ichhpujani, R.L.. Rajesh Bhatia. Medical Parasitology. First. JAYPEE; 1994. 1-3 p.

13. Jayaram Paniker, CK. Paniker's Textbook of medical parrasitology. Seventh. Sougata ghosh, editor. JAYPEE; 2013. 229-234 p.

14. Rajesh Karyakarte AD. Medical Parasitology. third. JAYPEE; 2012. 250$257 \mathrm{p}$.

15. Jayaram Paniker, CK. Paniker's Textbook of medical parrasitology. 7th edn. JAYPEE; 2013. 15 p.

16. Garcia L.S.; Ash L.R. Collection and preservation of faecal specimens, macroscopic and microscopic examination of faecal specimens, permanent stained smears, special techniques of stool examination. In: C.V. Mosby company, editor. Diagnostic parasitology Clinical Laboratory Manual. California; 1975. p. 123.

17. Jayaram Paniker, CK. Paniker's Textbook of medical parrasitology. 7th edn. JAYPEE; 2013. 30-32 p.

18. Jayaram Paniker, CK. Paniker's Textbook of medical parrasitology. 7th edn. JAYPEE; 2013. $111 \mathrm{p}$.

19. Rajesh Karyakarte AD. Medical parasitology. third. JAYPEE; 2012. 250$257 \mathrm{p}$.

20. Beena Jad, Sanjay Raina PSG. Prevalence of intestinal parasites among patients of a tertiary hospital in Ambala city, Haryana, India. Int J Res Med Sci. 2015; 3(12) :3753-8.

21. Khan H. Gastrointestinal diseases: frequency of symptoms. Prof Med J. 2008;15(2):459-64. 
22. S.L. Choubisa V. J. Jaroli Pallavi Choubisa, Mogra N. Intestinal parasitic infection in Bhil tribe of Rajasthan, India. J Parasit Dis. 2012;36(2):143-148.

23. Chang L, Toner BB, Fukudo S, Guthrie E, Locke GR, Norton NJ, et al., Gender, Age, Society, Culture, and the Patient's Perspective in the Functional Gastrointestinal Disorders. Gastroenterology. 2006; 130(5): 1435-46.

24. Halder SLS, Locke GR, Schleck CD, Zinsmeister AR, Melton LJ, Talley NJ. Natural history of functional gastrointestinal disorders: a 12-year longitudinal population-based study. Gastroenterology [Internet]. 2007;133(3):799-807. Available from: http://www.ncbi.nlm.nih.gov/pubmed/1767 8917\%5Cnhttp://dx.doi.org/10.1053/j.gastr o.2007.06.010

25. Patel JC. Ten year study of stool samples with particular reference to intestinal parasites. J Postgr Med. 1986; 32: 219 224.

26. Hedge GR PJ. Prevalence of intestinal parasitic infestation in rural area. J Postgr Med. 1986; 32: 225-228.

27. Bentley P, Parekh A, Snow MJ. Perceptions of anemia and health seeking behavior among women in four Indian states Technical Working Paper \# 9. Development. 1998; (October).

28. Sen J. A Sociological study on health seeking behavior of women withreference to hepatitis and gall bladder stone in south Assam. Ethno Med. 2012; 6(2): 131-9.

29. Borooah VK. On the incidence of diarrhoea among young Indian children. Econ Hum Biol. 2004; 21(1): 119-38.
30. Jad B et al., Prevalence of intestinal parasites among patients of a tertiary hospital in Ambala city, Haryana, India. Int J Res Med Sci. 2015; 3(12): 3753-8.

31. B. M. Shanker Venkatesh, S. Rajeshwar Rao, N.Vivekanand BMSV. A Comparative Study of Concentration Techniques for Detection of Intestinal Parasitic Infections - to Evaluate the Prevalence And to Identify A Better Method of Concentration Technique At A Tribal Tertiary Care Hospital. IOSR J Dent Med Sci. 2016; 15(7): 42-6.

32. Hersh AhmadAmin, SAA. Evaluation of Different Techniques of Stool Examination for Intestinal Parasitic Infections in Sulaimani City - Iraq. Int J Curr Microbiol Appl Sci. 2015; 4(5): 991-6.

33. Dr Ritu Garg VAS. Identification of parasitic infections in stool samples by different methods: a study emphasizing the use of concentration techniques. Sch J Appl Med Sci. 2017; 5(1C): 159-61.

34. Magdi Bayoumi, Opwonyi Nykwac, Mohammed Kardaman, Mans Ullberg EM, Alshammari, Gunnar Sandström, Amir Saeed HA. Intestinal Parasitic Infections in School Students in Malakal City, Upper Nile State, South Sudan. SOJ Microbiol Infect Dis. 2016; 4(1): 1-5.

35. Singh Randhir K., Dewasy Bijoylakshmi SJW and KTK. Prevalence of intestinal parasitic infection among different sex and age groups of patients attending Birat Medical College, Biratnagar Nepal. J Glob Biosci. 2017; 6(1): 4733-40.

36. B. Shakya, D. Bhargava, S. Shrestha BPR. Intestinal Parasitosis. J Inst Med. 2009; 31(3): 13-6.

\section{How to cite this article:}

Sourabh Chakraborty and Nilekar, S.L. 2019. Prevalence of Intestinal Parasitic Infestations in and Around Ambajogai, Maharashtra. Int.J.Curr.Microbiol.App.Sci. 8(03): 406-414. doi: https://doi.org/10.20546/ijcmas.2019.803.051 